\title{
Causas de la deserción escolar, en las telesecundarias de la zona 55
}

\author{
Paola Ortega Huerta ${ }^{1}$ \\ María José Macías Velasco ${ }^{2}$ \\ María del Rocío Hernández Jiménez ${ }^{3}$ \\ Asesor: Esther Fragoso Fernández
}

\section{Resumen}

La presente investigación fue realizada en cuatro telesecundarias de la Zona Escolar 55, que comprenden los municipios de Juárez Hidalgo y Tlahuiltepa, en el estado de Hidalgo; dichas comunidades son: San Lorenzo Iztacoyotla, Santa María, Acapa y San Nicolás.

El motivo de este trabajo partió de la necesidad de identificar las posibles causas de la deserción escolar en la zona antes mencionada, por lo que se inició con el proceso de la investigación.

Se comenzó con un primer acercamiento a la comunidad en donde se identificó el problema antes mencionado, después se procedió a sustentar toda la investigación con ayuda de teóricos y otras investigaciones que sirvieron de referencia a la problemática investigada.

Posteriormente, se construyeron los instrumentos que se aplicarían a los diferentes sujetos como alumnos, padres de familia y maestros, a quienes se les aplicaron entrevistas y listas de cotejo.

Después de su aplicación se realizó un análisis de los datos obtenidos, que dio como resultado que la deserción escolar, en tres de las comunidades, se debe a la falta de recursos económicos y en una de ellas a la falta de interés por parte de los alumnos.
Se concluyó con algunas propuestas para evitar la deserción escolar y tratar de trabajar conjuntamente padres y maestros.

\section{Introducción}

La investigación aborda el tema de la deserción escolar en el la Zona escolar 55 debido a las necesidades expresadas de ésta. Al realizar un trabajo de exploración previo se percató que la deserción escolar, entendida como la interrupción de los estudios, no se consideraba así en este lugar sino que la problemática principal hacía referencia a que los estudiantes no continúan con sus estudios de bachillerato. Según Del Castillo (2012) la deserción escolar también es el abandono de sus sueños y perspectivas de una vida futura provechosa y responsable que los llevaría a invalidar su futuro el cual no es mañana sino hoy.

Se tomaron en cuenta distintos autores que sustentaran las posibles causas de la deserción escolar en donde se encontró que existen factores familiares, escolares, sociológicos y cognitivos. Todo esto abrió un panorama más amplio en la investigación.

En este trabajo se muestra la metodología de una investigación cualitativa con sus respectivas partes y los resultados obtenidos.

1 p521orthuert_cat@hotmail.com. Sexto semestre de la Licenciatura en Ciencias de la Educación, ULSA Pachuca.

2 majo_mv1793@hotmail.com. Sexto semestre de la Licenciatura en Ciencias de la Educación, ULSA Pachuca.

3 mrhj265@yahoo.com.mx. Sexto semestre de la Licenciatura en Ciencias de la Educación, ULSA Pachuca. 


\section{Planteamiento del problema}

Las dificultades que se pueden encontrar en las escuelas podrían ser el acoso escolar, problemas con los profesores y/o directivos, deficiencia en las instalaciones, entre otros; pero existe otra situación que al igual que el acoso escolar, ha causado dificultades en la población estudiantil y esto es la deserción escolar.

A partir de un trabajo exploratorio se detectó que la problemática que se ha presentado en la Escuela Telesecundaria 22 de la comunidad de San Lorenzo Iztacoyotla del municipio de Juárez, Hidalgo y la zona escolar número 55 es la deserción escolar. Los alumnos concluyen con sus estudios básicos pero no continúan con su educación preparatoria.

La deserción escolar según el INEE (Instituto Nacional para la Evaluación de la Educación) en el ciclo escolar 2008-2009 en el país, el nivel de deserción escolar fue del $6.4 \%$, lo que equivale a 394785 hombres y mujeres que no concluyeron sus estudios de nivel secundaria aunque en el estado de Hidalgo el porcentaje es el más bajo a nivel nacional con un $4.0 \%$ en mujeres y en hombres el $5.1 \%$, (INEE, 2010). Al partir de estos datos y de la realidad de la comunidad de San Lorenzo Iztacoyotla, se podría decir que una de las causas más comunes del abandono escolar es que las familias presentan problemas económicos y al no poder cubrir los gastos de los estudios de sus hijos, el estudiante se ve obligado a abandonar la escuela y a encontrar un trabajo para ayudar a su familia. (Recuperado de http://www.inee.edu.mx/bie/mapa_indica/20 10/PanoramaEducativoDeMexico/AT/AT02/2 010_AT02_d-vinculo.pdf)

Es por eso que en este estudio trabajará en indagar las razones por las cuales los estudiantes renuncian a la escuela y así encontrar la manera que en conjunto con maestros, estudiantes, padres de familia, se busquen soluciones y puedan los alumnos forjarse un mejor futuro.

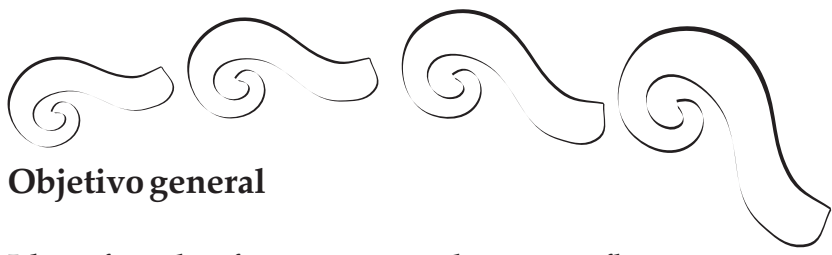

Identificar los factores centrales que influyen en la deserción escolar en alumnos de la zona escolar número 55, de los municipios de Juárez Hidalgo y Tlahuiltepacon el fin de proponer estrategias que permitan disminuir el abandono escolar.

\section{Objetivos específicos}

- Identificar qué aspectos de la situación económica y/o social son factores de la deserción escolar

- Detectar qué factores académicos contribuyen a la deserción escolar.

- Descubrir qué aspecto de la familia es un factor que contribuye a la deserción escolar.

- Determinar factores personales que llevan al estudiante a la deserción escolar.

- Desarrollar estrategias que permitan motivar a los alumnos a continuar con sus estudios.

\section{Preguntas de investigación}

1. ¿Cuáles son los factores que influyen en la deserción escolar de los alumnos de la zona escolar número 55 ?

2. ¿Qué aspectos académicos influyen en la deserción escolar?

3. ¿Cómo influyen los padres de familia en la deserción escolar que se presenta en los alumnos de la zona escolar número 55 ?

4. ¿Qué hacen los padres de familia para evitar la deserción escolar en sus hijos?

5. ¿Cuál es el papel de los docentes en la prevención de la deserción escolar?

6. ¿Qué estrategias se pueden implementar para motivar a los alumnos de la zona escolar número 55 y evitar de esta manera la deserción escolar? 


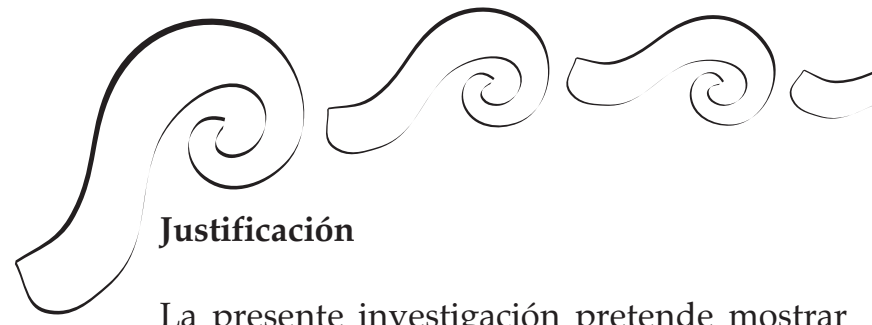

de qué manera se puede in tervenir para mejorar la situación que tienen los jóvenes con tendencia a la deserción escolar a partir de los factores identificados que influyen en la problemática, así como el trabajo que se puede realizar con los maestros para motivar a los estudiantes y que estos puedan continuar con sus estudios posteriores y en un futuro poder insertarse en el mundo laboral y alcanzar mejores condiciones de vida, así como motivar a los padres de familia para que intervengan y participen activamente en esta problemática de la escuela.

El proyecto PERLA (Proyecto Educativo Regional Lasallista Latinoamericano), presenta lineamientos al que la presente investigación pretende responder desde la quinta urgencia, la cual dicta que es necesaria una “Educación en y desde el respeto a los derechos humanos, especialmente de la niñez y de la juventud"; por lo tanto, una de las posibles razones de la deserción escolar es la carencia de recursos económicos en la comunidad, y esto orilla a los jóvenes a dejar sus estudios e insertarse en el mundo laboral a temprana edad, lo que violenta sus derechos humanos. (La Salle 2011)

De igual manera a partir del Proyecto PERLA se hace alusión a la primera urgencia llamada "Democratización del conocimiento", en la cual una de sus líneas de acción comprende el "desarrollar espacios y programas educativos formales y no formales para que las comunidades excluidas mejoren sus condiciones de vida y sean sujetos de su propio destino". (La Salle 2011)

Para concluir, los elementos que se tienen a favor es el apoyo de la dirección escolar que ha abierto el espacio para poder realizar esta intervención y la cual hace viable la presente actividad, así como el apoyo de la Universidad La Salle Pachuca, que permite realizar este trabajo de campo.

\section{Marco Teórico}

\section{Marco histórico}

La población que se atenderá son las telesecundarias de la Zona Escolar 55, por lo que es importante hacer referencia a la historia de las Telesecundarias mismas.

Las telesecundarias surgieron en México en el año de 1968 y con ello inició una nueva época en la educación mexicana. Surge por el rezago educativo sobre todo en zonas rurales, casi el $80 \%$ de la población era analfabeta. (Jiménez Hidalgo, J. d., Martínez Jiménez, R., \& García Mancilla, C. D. 2010)

Los elementos de las escuelas telesecundarias son principalmente: las clases televisadas, guías de aprendizaje, conceptos básicos y la presencia del profesor.

El 17 de agosto de 1965 se anunciaron por primera vez en el periódico Novedades, el proyecto de Alfabetización y el de Educación Secundaria por televisióncon los siguientes objetivos:

1. Completar el servicio de educación media ofrecido por la Secretaría de Educación Pública.

2. Poner a prueba técnicas audiovisuales para la escuela secundaria.

3. Abrir nuevas perspectivas de trabajo para los maestros mexicanos.

4. Llevar a los hogares conocimientos útiles, dosificados $\mathrm{y}$ sistematizados pedagógicamente.

5. Hacer llegar los beneficios del servicio a todos los mexicanos que por diversas causas no recibieron más que la educación primaria.

Además, proporcionar sugerencias didácticas a los profesores de las escuelas secundarias que estimen conveniente utilizar las emisiones de la telesecundaria como auxiliares de enseñanza. (Jiménez Hidalgo, Martínez Jiménez, \& García Mancilla, 2010) 


\section{Marco conceptual}

Los conceptos que se tomarán en cuenta son:

\section{a) Adolescencia}

Existe una tendencia de parte de los jóvenes al estar en una etapa de efervescencia de la edad, en donde creen saber todo, no están en disposición de escuchar a los adultos y hacer caso omiso a lo que los mayores le digan.

Según Papalia, Wendkos \& Duskin (2005) "La adolescencia es una transición del desarrollo entre la niñez y la edad adulta que implica importantes cambios físicos, cognoscitivos y psicosociales, asimismo, la adolescencia comienza con la pubertad, que es el proceso que conduce a la madurez sexual o fertilidad, es decir, la capacidad para reproducirse. La adolescencia dura aproximadamente entre 11 o 12 años a los 19 o inicio de los 20, y conlleva cambios ínterrelacionados en todas las áreas del desarrollo. La adolescencia es una construcción social". (p. 427)

Según Hurlock (2007, p.15) la palabra "adolescencia" proviene del verbo latino adolescere, que significa "crecer" o "crecer hacia la madurez". La adolescencia es un periodo de transición en el cual el individuo pasa física y psicológicamente desde la condición de niño a la de adulto.

Complementando el concepto anterior, Sorenson citado en Hurlock(2007, p.15)

"La adolescencia es mucho más que un peldaño en la escala que sucede a la infancia. Es un periodo de transición constructivo, necesario para el desarrollo del yo. Es una despedida de las dependencias infantiles y un precoz esfuerzo por alcanzar el estado adulto"

\section{b) Deserción escolar}

Según la Real Academia Española (2014) la palabra deserción proviene del latín desertio, -

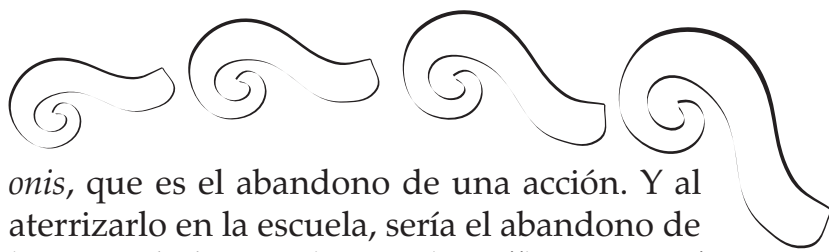

las actividades escolares. (http://lema.rae.es/ drae/?val=deserci $\%$ C3\% B3n+escolar)

Por otro lado, en el diccionario de las Ciencias de la Educación, la deserción escolar es el abandono del centro escolar y de los estudios por parte del alumno debido a motivos personales, familiares, sociales, etc. (Santillana, 1983)

También se puede ver que según (Del Castillo, 2012, p. 14) la deserción escolar

"no es más que el abandono de parte de los educandos y educadores si nos referimos a las instituciones educativas, no sólo de las aulas donde se adquieren conocimientos, sino también el abandono de sus sueños y perspectivas de una vida futura provechosa y responsable que lo llevaría a invalidar su futuro el cual no es mañana sino hoy".

La deserción escolar según (Espíndola, 2002) es:

"El resultado de un proceso en el que intervienen múltiples factores y causas, algunos de los cuales son característicos de los niños y jóvenes y de sus situaciones socioeconómicas (factores extraescolares), y de otros más asociados a las insuficiencias del propio sistema educativo (factores intraescolares)".(p.52)

Para el presente trabajo, la deserción escolar será entendida como el abandono y suspensión de los estudios escolares posteriores por causas familiares, económicas, desmotivación y falta de credibilidad en la escuela, así como falta de centros de estudios superiores en la misma zona.

\section{Marco teórico}

Según Del Castillo (2012) la deserción escolar no es más que el abandono de parte de los educandos y educadores, si nos referimos a las instituciones educativas, no sólo de las aulas 


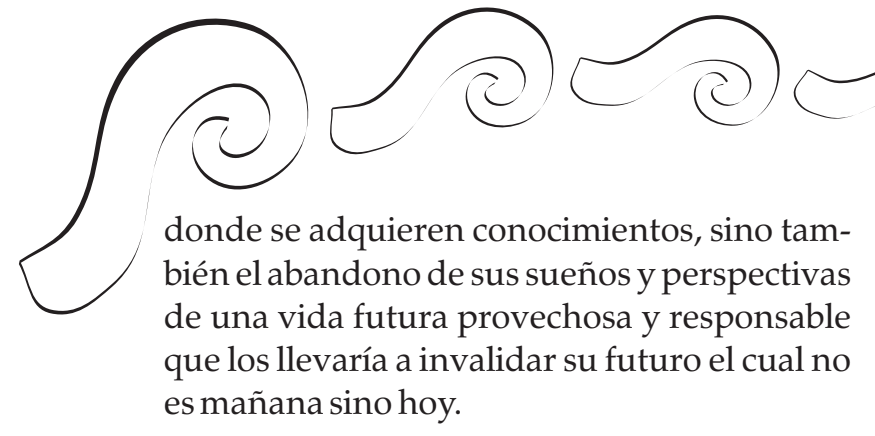

Otra forma de llamar a la deserción escolar es fracaso escolar, como afirma Crispo (2001); esta psicóloga dice que lo que ha sido llamado por diversos autores "fracaso escolar" describe a los adolescentes que no han completado el ciclo básico, aunque también entran en este grupo los alumnos repitientes, que años tras año quedan con materias por aprobar y que finalmente abandonan la escuela.

También menciona que si bien los índices de escolarización en los países industrializados han aumentado, de igual forma han aumentado los índices de jóvenes que fracasan o se encuentran marginados antes de haber terminado su escolaridad obligatoria. En efecto, un porcentaje, notable de adolescentes, generalmente perteneciente a las clases sociales más desfavorecidas, no continúa sus estudios más allá del ciclo básico, o los abandona sin haber alcanzado ninguna calificación. Los autores están hoy de acuerdo en sostener que las causas del fracaso escolar obedecen a tres órdenes: sociológico, psicológico y pedagógico. Es habitual que estos factores se entrecrucen, por lo que para comprender las causas de los fracasos escolares hay que atender su interacción y sus efectos independientes, (Crispo, 2001).

Como causas sociológicas se establecen aquellas vinculadas a la pobreza, esto es las condiciones de vida en la que viven las familias, la marginación, lugares en donde no se cuentan con escuelas aunada a que los alumnos con escasos recursos sean más susceptibles a tener problemas escolares y que estén en desventaja en el desarrollo de sus aptitudes intelectuales. A nivel social, los especialistas tienen claro que hay que ayudar a los jóvenes que debido a su origen y condiciones socioeconómicas tienen imposibilitado el acceso a la escolaridad media o presentan dificultades de integración.
Los factores psicológicos que contribuyen a una buena o mala escolaridad están vinculados a la seguridad del adolescente, la estabilidad de su familia, sus aptitudes mentales, su capacidad de atención y concentración, el estímulo a su desempeño y los límites a sus conductas. Muchas veces los problemas escolares aparecen como emergentes de dificultades personales o familiares, se ha comprobado que las problemáticas escolares merman cuando el adolescente cuenta con apoyo personal y afectivo de parte de los adultos.

Se trata en consecuencia de alterar a la familia para involucrarla en la solución de la problemática y también se pretende que en el caso de no contar con esta ayuda, un profesor, preceptor o psicopedagogo establezcan un vínculo especial con el chico que tiene dificultades. En algunos colegios se ha implementado ya la inclusión de gabinetes de profesionales que brindan asesoramiento y orientación a los adolescentes y a sus padres en caso de sufrir este tipo de problemas, la cual es una práctica que debería extenderse. Una orientación adecuada a tiempo o el tener con quién conversar le permite muchas veces al joven resolver su conflicto y comenzar a funcionar de forma diferente.

La tercera cuestión está ligada con el sistema educativo en general y la escuela particular. Desde cómo se califica en el colegio, cuál es la organización de las tareas, qué relaciones se establecen entre docentes y alumnos, hasta aspectos disciplinarios y curriculares. $Y$ en este punto es necesario que nos detengamos para atender qué esperan los jóvenes de la escuela y qué encuentran realmente.

Por otro lado, Joan Romeu I Bes (en Callabed Joaquín, 2002) afirma que es posible evitar que el adolescente deje la escuela, ya que éste no es el responsable de la situación porque solo vive las consecuencias de una realidad.

La deserción escolar tiene diferentes causas pero es difícil poder determinar culpabilidad 
en los padres, ya que todo padre quiere lo mejor para sus hijos y espera de ellos lo máximo, por ello proporciona elementos y medios necesarios que en ocasiones no está dentro de sus posibilidades.

Como también son muchos los padres que no le dan prioridad a las necesidades de soporte y apoyo que necesitan sus hijos en los estudios y dejan así todo el trabajo a los maestros, olvidando que los padres son insustituibles, estos se excusan y muchas veces son sobradas razones como son: educación, situación laboral, migratoria, idioma, falta de recursos comunitarios, estabilidad económica, inseguridad en general.

Si no se les enseña a los hijos correctamente, después existirán problemas que podrán ser la causa de la deserción escolar. Los valores se aprenden en casa y se ponen en práctica en la escuela, por lo que si los padres dicen algo y no lo cumplen, entonces ¿qué es lo que realmente le enseñan a los hijos?

Sencillamente los padres quieren siempre lo mejor para sus hijos y son los primeros en confundirlos con una actitud permisiva y complaciente, ya sea por desconocimiento o por una falsa competencia de ser mejor que cualquier otro padre.

Una de las interrogantes es por qué a estos jóvenes no se les preparan para luchar y salir airosos de las presiones de grupos que reciben de sus amigos en el aula. Pues tenemos que entender que muchos de los padres de estos, no tienen tal vez la preparación que les permita ayudarlos. Su falta de conocimiento sobre los recursos comunitarios a su alcance los limita, es de aquí la importancia que las instituciones educativas integren a los padres y los tutores al sistema escolar de sus hijos.

Otra de las posibles causas de la deserción escolar es la pérdida de los valores. Los valores parecen extinguirse cada día más en el afán de la obtención de cosas materiales a los hijos.

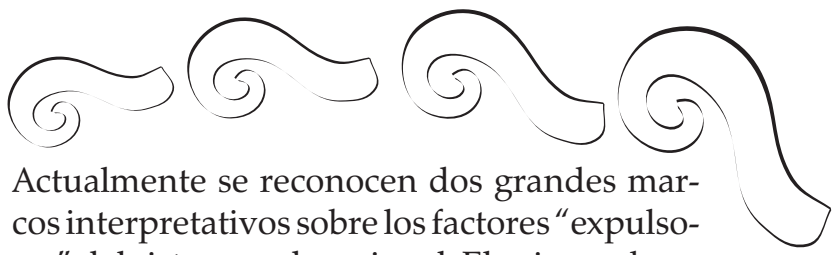

res" del sistema educacional. El primero hace hincapié en la situación socioeconómica y en el contexto familiar de los niños y jóvenes como fuentes principales de diversos hechos que pueden facilitar directa o indirectamente el retiro escolar; como pueden ser las condiciones de pobreza y marginalidad, adscripción laboral temprana, anomia familiar, adicciones, etc., y se encamina a la responsabilidad en la producción y reproducción de estos factores a agentes de naturaleza extraescolar: el Estado, el mercado, la comunidad, los grupos de pares y la familia. La organización familiar cobra un papel importante pues son posibles fuentes de desamparo, violencia y hasta promiscuidad. Problemas como el consumo de drogas o alcohol y embarazo adolescente también son manifestaciones de "anomia" que facilitan el retiro escolar. (Espíndola, 2002) El segundo marco interpretativo del que habla Espíndola hace referencia a las situaciones intrasistema que hacen conflictiva la permanencia de los estudiantes en la escuela: bajo rendimiento, problemas conductuales, autoritarismo docente, etc. De esta manera sería la escuela la responsable directa de la expulsión de los alumnos.

La investigación de Espíndola concluye que la escuela no integra sino que a menudo segrega a los estudiantes de las clases desfavorecidas con bajas calificaciones y con la inevitable tendencia hacia el fracaso escolar; los juicios de los profesores les convencen de que son incapaces de estudiar y que deben contentarse con un trabajo modesto, adaptado a sus capacidades. Para muchos niños y jóvenes de los estratos pobres la calle se convierte así en el ámbito de socialización entre pares en el que logran mayor satisfacción, mientras que la escuela se manifiesta como la primera experiencia de fracaso social. (Espíndola, 2002).

\section{Marco referencial}

La investigación realizada por Espinoza, Castillo, González, \& Loyola (2012), en la Uni- 


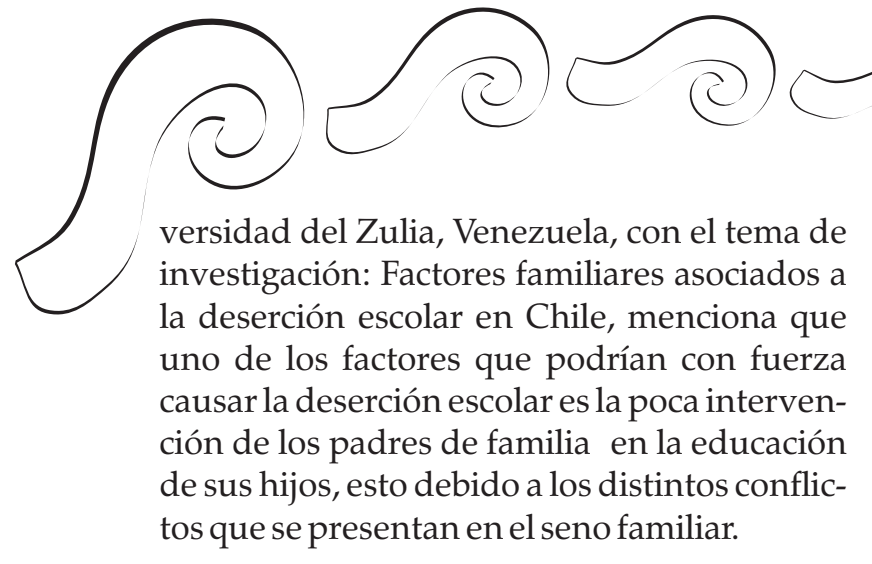

Es por ello que al considerar esta investigación, se resaltan elementos que podrían contribuir a la iluminación del tema al que se hace referencia al principio.

En otra investigación realizada por el Dr. Salvador Cárdenas nos explica con una encuesta realizada a 64,000 niños de México, los motivos por los que dejaron de ir a las aulas escolares:

“El 6.6\% de ellos nunca había asistido a la escuela, el $34.3 \%$ dejó de asistir a la escuela porque no le gustó estudiar, $22.1 \%$ porque tuvo que trabajar, el $1.5 \%$ fue porque se casó o unió con alguna pareja, $1.5 \%$ argumentó que se encontraban viviendo en una zona lejana de la institución escolar o porque no existía alguna institución cercana a ellos, $28 \%$ tuvo otro motivo, como puede ser enfermedad y $4.5 \%$ no especificó por qué dejó de asistir a la escuela." (Cárdenas, 2014,p. 1)

Con esta investigación, nos damos cuenta que no solamente los problemas económicos y los problemas familiares influyen en la deserción escolar, sino también la falta de interés en el estudio, según Cárdenas (2014, p. 2):

"En Latinoamérica, en países como México, 37\% de los adolescentes abandonan la escuela antes de completar la secundaria, es decir, un poco más de una tercera parte. La mitad de ese $37 \%$ abandona la escuela sin terminar siquiera la educación primaria. Estamos hablando de porcentajes muy altos, no es algo aislado, no es un asunto que se diga solamente de un estado o de unas cuantas personas que están pasando esto, sino que estamos hablando de porcentajes muy altos y un porcentaje mayor todavía que no termina la educación secundaria."
Otro estudio realizado afín a la presente investigación es la de Ernesto Espíndola titulada "La deserción escolar en América Latina: un tema prioritario para la agenda regional", da a concoer que a pesar de la importante disminución de las tasas de deserción en América Latina en los últimos 10 años, los adolescentes del $25 \%$ de los hogares urbanos de menores ingresos presentan tasas de abandono escolar que, en promedio, triplican a la de los jóvenes del $25 \%$ de los hogares de ingresos más altos. $(2002$, p.45)

Como afirma Espíndola:

"Estas desigualdades entre estratos socioeconómicos extremos son mayores en el medio urbano que en el rural; mucho más elevadas cuando se refieren al abandono temprano de la escuela y, por regla general, superiores en los países de la región que han avanzado en mayor medida hacia la universalización del acceso a la educación primaria y secundaria." (Espíndola 2002, p.58)

\section{Metodología}

\section{Enfoque}

El enfoque de la presente investigación es de corte cualitativo porque se realizarán entrevistas semiestructuradas que permitirán ahondar sobre las experiencias de los alumnos, padres de familia y maestros respecto a la problemática antes presentada: la deserción escolar, además de ser flexible con la situación de cada persona.

La investigación es cualitativa también porque se hará un trabajo de campo observando el desarrollo del fenómeno a estudiar en su estado natural, no se pretende alterar la realidad sino comprenderla, además la recolección de datos es confiable al estar vinculada con los parámetros establecidos dentro de la investigación científica. 


\section{Contexto}

La investigación fue realizada en las telesecundarias: 22 de San Lorenzo Iztacoyotla, 346 de Santa María, 116 de Acapa y 598 de San Nicolás de la Zona 55, que comprenden los municipios de Juárez Hidalgo y Tlahuiltepa.

\section{Alcance}

El alcance de la presente investigación es descriptivo ya que establecerá las principales características de las posibles causas de la deserción escolar y mencionar en qué consiste cada una, así como su desarrollo en el sujeto de estudio y su repercusión en la comunidad. También se enunciarán las características del contexto, las personas implicadas en la situación planteada anteriormente, así como el contexto en donde están ubicados y las problemáticas externas que contribuyen en la deserción escolar.

Esta investigación se abre a los hechos porque en ésta se buscan las causas de la deserción escolar y las estrategias que podrían usarse para evitarla, también es válida porque se muestra el nivel de verdad que tiene el sujeto y sus aportes a la investigación.

\section{Diseño}

El diseño de esta investigación será no experimental puesto que se tratará de alterar la realidad en lo más mínimo, por lo que quedará en su estado natural.

Así también se estudiará de manera transeccional, ya que solo se estudia el caso concreto de la deserción escolar en un tiempo concreto, puesto que la falta de tiempo impide continuar con la investigación, pero queda abierta a futuras investigaciones y observar de esta manera la evolución de la situación presentada.

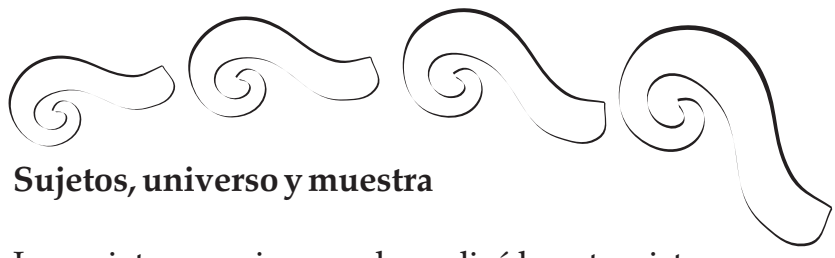

Los sujetos a quienes se les aplicó la entrevista fueron: alumnos, padres de familia y profesores correspondientes a las cuatro telesecundarias de la Zona Escolar 55.

La muestra fue del $20 \%$ de la población. El número de entrevistados fueron 66 de todas las escuelas.

\section{Instrumentos de recolección}

Los instrumentos que se utilizaron fueron entrevistas y listas de cotejo, las cuales se aplicaron a padres de familia, alumnos y docentes de las telesecundarias de la Zona Escolar 55 que comprende las comunidades de San Lorenzo Itztacoyotla, Santa María, Acapa y San Nicolás.

Se aplicaron nueve entrevistas y nueve listas de cotejo a nueve alumnos de tercero de secundaria en cada escuela. Cinco entrevistas y cinco listas de cotejo a cinco padres de familia a las respectivas escuelas. Por último, cuatro entrevistas y cuatro listas de cotejo a cuatro docentes. Los sujetos fueron elegidos al azar.

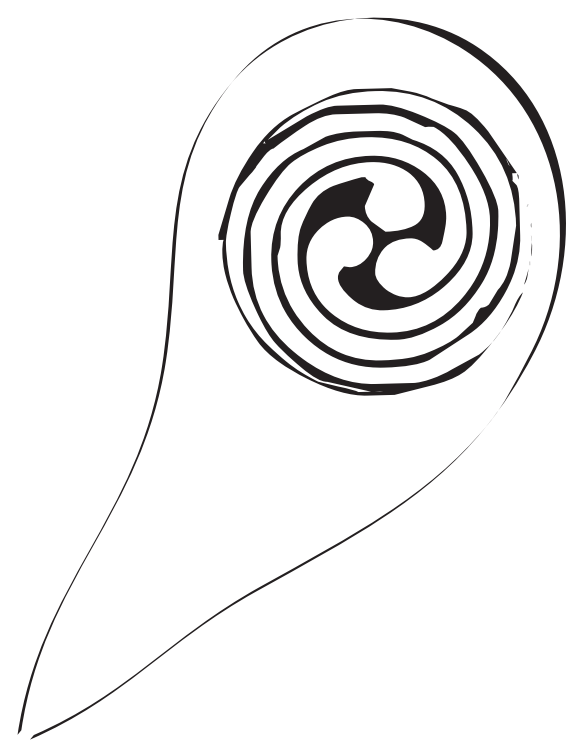


Folio:

ENTREVISTA A LOS ALUMNOS DE LAS TELESECUNDARIAS DE LA ZONA ESCOLAR 55

NOMBRE:

ESCUELA:

\section{INSTRUCCIONES: Contesta las preguntas con sinceridad}

1. ¿Qué piensas acerca del apoyo que la escuela te ofrece para continuar tus estudios? R.

2. ¿Qué propones tú para mejorar a la escuela?

R.

II. Elige en las siguientes preguntas la respuesta que se asemeja a tu modo de pensar:

3. ¿Qué importancia tiene estar en la escuela?

a. Es importante para conseguir un empleo.

b. Para que la persona trascienda y se forme integralmente.

c. Para aprender cosas nuevas.

d. Para tener aquellas oportunidades que no tuvieron mis papás.

e. Para que no me queden en casa sin hacer nada.

f. No tiene ninguna importancia.

4. ¿Qué es la Deserción Escolar?

a. No sé.

b. Se refiere cuando los alumnos dejan de estudiar.

c. Cuando los alumnos repiten de año.

d. Cuando los alumnos ya no continúan con los estudios posteriores.

e. Cuando no continúan sus estudios posteriores y abandonan la escuela.

5. ¿Cuál es la causa principal por la que algunos alumnos desertan en la escuela? a. Por falta de recursos económicos.

b. Por falta de interés en la escuela.

c. Oportunidad laboral.

d. Por problemas familiares.

e. Problemas de aprendizaje.

f. Otro

6. ¿Cómo afecta la deserción escolar en tu comunidad?

a. Los alumnos no encontramos trabajo.

b. La comunidad no tiene oportunidad de prosperar.

c. La gente se queda con los estudios básicos o nulos.

d. No afecta en gran medida.

e. Otro

7. ¿Qué podrías hacer para evitar la deserción escolar?

a. Buscar ayuda de mis padres.

b. Pedirle ayuda a mis maestros.

c. Buscar una beca poder continuar mis estudios.

d. Esforzarme un poco más en mis estudios.

e. Nosé

8. ¿Cómo es tu participación en la escuela?

a. Solo asisto a las clases de manera cumplida.

b. Participo activamente en todas las actividades extras de la escuela.

c. Apoyo y doy ideas al director o a los maestros cuando surge algún problema.

d. Falto muchas veces a la escuela.

e. Otro
SEXO:F( ) M( )

EDAD:

Observaciones 
Folio:

ENTREVISTA A LOS PADRES DE FAMILIA DE LOS ALUMNOS DE LAS TELESECUNDARIAS DE LA ZONA ESCOLAR 55

NOMBRE:

SEXO:F( ) M( )

ESCUELA:

GRADO:

EDAD:

I. INSTRUCCIONES: Contesta las siguientes preguntas con sinceridad

Observaciones

1. ¿Qué piensa acerca del apoyo que la escuela ofrece a su hijo para motivarlo a continuar sus estudios?

R.

2. ¿Qué propones tú para mejorar a la escuela?

R.

II. Elige de las siguientes preguntas la respuesta que se acerque a tu forma de pensar.

3. ¿Qué importancia tiene estar en la escuela?

a. Es importante para conseguir un empleo.

b. Para que la persona trascienda y se forme integralmente.

c. Para aprender cosas nuevas.

d. Para que tengan aquello que yo no tuve.

e. Para que no se queden en casa sin hacer nada.

4. ¿Qué es la Deserción Escolar?

a. No sé.

b. Se refiere cuando los alumnos dejan de estudiar.

c. Cuando los alumnos repiten de año.

d. Cuando los alumnos ya no continúan con los estudios posteriores.

e. Cuando no continúan sus estudios posteriores y abandonan la escuela.

5. ¿Por qué los alumnos dejan sus estudios?

a. Por falta de recursos económicos.

b. Por falta de interés en la escuela.

c. Oportunidad laboral.

d. Por problemas familiares.

e. Problemas de aprendizaje.

6. ¿Cómo es su participación en la escuela?

a. Está al pendiente de cómo va su hijo (a) en la escuela.

b. Recoge las calificaciones de sus hijos (as).

c. Asiste a las reuniones de padres de familia.

d. Participa en las actividades que propone la escuela en beneficio de los alumnos.

7. ¿Cómo afecta la deserción escolar a la comunidad?

a. Los alumnos no encuentran trabajo.

b. La comunidad no tiene oportunidad de prosperar.

c. La gente se queda con los estudios básicos o nulos.

d. No existe un pensamiento crítico y la gente puede ser manipulable.

e. No afecta en gran medida.

8. ¿Qué podrías hacer para evitar la deserción escolar?

a. Hablar con mi hijo para que no deje la escuela.

b. Obligar a mi hijo asistir a la escuela.

c. Involucrarme con los maestros y estar al pendiente de mi hijo.

d. Dejar que él tome sus decisiones.

e. Orientarlo

f. No sé 
Folio:

\section{ENTREVISTA A MAESTROS DE LAS TELESECUNDARIAS DE LA ZONA ESCOLAR 55}

NOMBRE:

ESCUELA:

I. INSTRUCCIONES: Contesta las siguientes preguntas con sinceridad
SEXO:F( ) M( ) EDAD:

Observaciones

1. ¿Qué piensa acerca del apoyo que la escuela ofrece a los alumnos para motivarlo a continuar sus estudios?

R.

2. ¿Qué propones para mejorar la práctica escolar en cuestión de las estrategias didácticas para evitar la deserción escolar?

R.

II. Elige de las siguientes preguntas la respuesta que se acerque a tu forma de pensar.

3.- ¿Qué importancia tiene la escuela?

a. Es importante para conseguir un empleo.

b. Para que la persona trascienda y se forme integralmente.

c. Para aprender cosas nuevas.

d. Para que los alumnos desarrollen sus potencialidades.

e. Para que no se queden en casa sin hacer nada.

f. No tiene ninguna importancia.

4. ¿Qué es la Deserción Escolar?

a. No sé.

b. Se refiere cuando los alumnos dejan de estudiar.

c. Cuando los alumnos repiten de año.

d. Cuando los alumnos ya no continúan con los estudios posteriores.

e. Cuando no continúan sus estudios posteriores y abandonan la escuela.

5. ¿Por quélos alumnos desertan de la escuela?

a. Por falta de recursos económicos.

b. Por falta de interés en la escuela.

c. Oportunidad laboral.

d. Por problemas familiares.

e. Problemas de aprendizaje.

f. otro

6. ¿Cómo afecta la deserción escolar en tu comunidad?

a. Los alumnos no encuentran trabajo.

b. La comunidad no tiene oportunidad de prosperar.

c. La gente se queda con los estudios básicos o nulos.

d. No existe un pensamiento crítico y la gente puede ser controlada.

e. No afecta en gran medida.

f. Otro

7. ¿Qué estrategias emplearías para evitar la deserción escolar?

a. Abriría un espacio de comunicación con los padres.

b. Mostrar los escenarios de aquellos que desertan en la escuela.

c. Contar historias de vida exitosas gracias a su formación educacional

d. Enseñar la importancia que tiene la educación para el progreso de una persona y su comunidad.

e. Mejorar las prácticas educativas

8. ¿Qué haces tú para evitar la deserción escolar? 
Folio:

\section{LISTA DE COTEJO A PROFESORES DE LAS TELESECUNDARIAS DE LA ZONA ESCOLAR 55}

NOMBRE:

SEXO:F( ) M( )

ESCUELA:

ESCOLARIDAD: EDAD:

\begin{tabular}{|c|c|c|}
\hline LISTA DE COTEJO PARA PROFESORES & Sí & NO \\
\hline 1. ¿Está enterado si sus alumnos, repasan sus materias fuera de los horarios de clase? & & \\
\hline $\begin{array}{l}\text { 2. Cuando algún alumno tiene una duda acerca del tema, ¿atiende a esa duda y la resuelve o } \\
\text { busca los medios para ello? }\end{array}$ & & \\
\hline $\begin{array}{l}\text { 3. ¿Los padres de familia apoyan a sus hijos cuando tienen problemas en la escuela, por } \\
\text { ejemplo si tiene alguna materia reprobada o problemas con algún compañero de salón? }\end{array}$ & & \\
\hline 4. ¿Existe un ambiente de respeto en el salón? & & \\
\hline 5. ¿Sabe si alguno de sus alumnos ya no continuará sus estudios por irse a trabajar? & & \\
\hline 6. ¿Emplea alguna estrategia para evitar la deserción escolar? & & \\
\hline 7. ¿Sus alumnos expresan el gusto o disgusto por las clases? & & \\
\hline 8. ¿Siente que su alumno ya no está a gusto en la escuela? & & \\
\hline $\begin{array}{l}\text { 9. ¿La falta de bachilleratos cercanos a la región es una causa por la que los alumnos dejan la } \\
\text { escuela? }\end{array}$ & & \\
\hline 10. ¿La situación económica de las familias contribuye a que los alumnos dejen la escuela? & & \\
\hline
\end{tabular}

Folio:

LISTA DE COTEJO A PADRES DE FAMILIA DE LOS ALUMNOS DE LAS TELESECUNDARIAS DE LA ZONA ESCOLAR 55

NOMBRE:

ESCUELA:
ESCOLARIDAD:
SEXO:F( ) M( ) EDAD:

\begin{tabular}{|c|c|c|c|}
\hline LISTA DE COTEJO PARA PADRES DE FAMILIA & Sí & NO & \multirow{11}{*}{ Observaciones } \\
\hline 1. ¿Su hijo (a) dedica un tiempo para estudiar, fuera de los horarios de clase? & & & \\
\hline 2. ¿Sabe si el profesor le explica a su hijo (a) cuando no le entiende a las materias? & & & \\
\hline $\begin{array}{l}\text { 3. ¿Apoya a su hijo cuando presenta alguna dificultad en la escuela, por ejemplo: } \\
\text { si reprueba alguna materia, o no hay entendimiento con el profesor o se pelea } \\
\text { con algún compañero? }\end{array}$ & & & \\
\hline 4. ¿Existe un ambiente de respeto en el salón de clases de su hijo? & & & \\
\hline 5. ¿Su hijo le tiene confianza como para contarle todo lo que le pasa? & & & \\
\hline 6. ¿Su hijo (a) le ha comentado que quisiera dejar los estudios por irse a trabajar? & & & \\
\hline $\begin{array}{l}\text { 7. ¿Su hija (o) platica con usted lo que hace en la escuela, cómo se siente, lo que le } \\
\text { preocupa, en conclusión, tiene una comunicación cercana con su ella o él? }\end{array}$ & & & \\
\hline 8. ¿Siente que su hijo ya no está a gusto en la escuela? & & & \\
\hline $\begin{array}{l}\text { 9. ¿Cuenta la posibilidad económica para que sus hijos continúen con sus } \\
\text { estudios? }\end{array}$ & & & \\
\hline 10. ¿Tiene alguna estrategia para evitar que su hija (o) deje la escuela? & & & \\
\hline
\end{tabular}


Folio:

LISTA DE COTEJO A LOS ALUMNOS DE LAS TELESECUNDARIAS DE LA ZONA ESCOLAR 55

NOMBRE:

SEXO:F( ) M( )

ESCUELA: ESCOLARIDAD: EDAD:

\begin{tabular}{|c|c|c|c|}
\hline LISTA DE COTEJO PARA ALUMNOS & Sí & NO & \multirow[t]{11}{*}{ Observaciones } \\
\hline 1. ¿Dedicas un tiempo para estudiar lo visto en clase? & & & \\
\hline 2 ¿El profesor (a) te explica algún tema cuando no lo entiendes o se te dificulta? & & & \\
\hline $\begin{array}{l}\text { 3. ¿Recibes apoyo de tus padres cuando tienes alguna dificultad en la escuela, } \\
\text { por ejemplo, si tienes alguna materia reprobada, dificultades con algún } \\
\text { profesor o compañero de clases? }\end{array}$ & & & \\
\hline 4. ¿Existe un ambiente de respeto en tu salón de clase? & & & \\
\hline 5. ¿Has pensado no continuar con tus estudios por irte a trabajar? & & & \\
\hline 6. ¿Les tienes confianza a tus padres para contarles lo que te pasa? & & & \\
\hline 7. ¿Le tienes confianza a tus profesores para contarles lo que vives? & & & \\
\hline 8. ¿Te gusta la escuela? & & & \\
\hline 9. ¿Tienes pensado continuar tus estudios de bachillerato? & & & \\
\hline 10. ¿Son de tu interés todas las materias que tienes en la escuela? & & & \\
\hline
\end{tabular}

\section{Análisis cualitativo}

De los instrumentos aplicados a cada uno de los sujetos, se realizó un análisis por escuela y se obtuvieron los siguientes datos:

\section{Telesecundaria 22, San Lorenzo Iztacoyotla}

Se realizó una investigación sobre la Deserción Escolar en la Telesecundaria 22 en la comunidad de San Lorenzo Iztlacoyotla, el día lunes 10 de noviembre. Los instrumentos utilizados para esta investigación fueron: la entrevista y la Lista de cotejo, las cuales se les aplicaron a los alumnos de tercero de secundaria, a padres de familia y a los docentes.

Se aplicaron los instrumentos a nueve alumnos de tercero de secundaria, varios de ellos se mostraban muy interesados en la investigación. Los instrumentos para padres de familia fueron aplicados cuando estos llegaban a dejarles el lunch a sus hijos.
Se pudo apreciar durante la aplicación de instrumentos, que los padres de familia de la comunidad de San Lorenzo están al pendiente de la educación de sus hijos. Expresaron que el apoyo que la escuela ofrece para la educación de sus hijos es muy buena, solo que el $76 \%$ de la comunidad pide que haya más recursos tecnológicos, ya que en estos tiempos se ha vuelto fundamental para todos.

Cuando se les preguntó sobre "la importancia de estar en la escuela", el 44.4\% de los alumnos, el $60 \%$ de padres de familia y el $66.6 \%$ maestros respondió que la escuela es importante para que la persona trascienda. Cuando se pide la definición de Deserción Escolar, el $44 \%$ de los alumnos y el $40 \%$ de padres de familia no sabía la definición del término; el otro $44 \%$ de alumnos y el $40 \%$ de padres, así como el $66 \%$ de maestros, mencionaron que 
es cuando no continúan con sus estudios posteriores y el $11 \%$ de alumnos, el $20 \%$ de padres y el $33 \%$ de maestros dijeron dijo que es cuando los alumnos dejan los estudios definitivamente.

En la cuestión acerca de la razón por la que dejan los estudios, el $66.6 \%$ de los alumnos, el $80 \%$ de padres de familia y el $100 \%$ de los maestros respondieron que es por la falta de recursos económicos; solo el $33.3 \%$ de los alumnos dijeron que se abandonan los estudios por falta de interés ya que los padres y maestros no mencionaron este punto y solo el $20 \%$ de los padres de familia afirmaron que la deserción se da por problemas de aprendizaje.

Al hablar de la afección sobre la deserción a la comunidad el $77.7 \%$ de los alumnos, el $66.6 \%$ de maestros y el $20 \%$ de los padres de familia menciona que los que desertan se quedan con los estudios básicos, el $11 \%$ de alumnos y el $60 \%$ de padres de familia dicen que no encuentran trabajo y el último punto en donde agregan que la comunidad no prospera el $11.1 \%$ de los alumnos, el $33 \%$ maestros y $20 \%$ padres tienen esta opinión.

Para evitar la deserción escolar, el 55.5\% de los alumnos respondieron que se esforzarían más en los estudios, por su parte el $40 \%$ de los padres de familia respondieron el hablar con sus hijos para que no dejen los estudios y el $66 \%$ de los profesores dicen que la estrategia es motivar a los alumnos y hablar con los padres de familia.

Para concluir el 100\% de los padres de familia afirma que a pesar de la situación económica que viven, están dispuestos a apoyar a sus hijos para que continúen con sus estudios. Y el $100 \%$ de los alumnos mencionó que desea continuar con sus estudios en tanto sus papás los apoyen.

\section{Telesecundaria 346, Santa María}

Se realizó una investigación en la comunidad de Santa María, en la Telesecundaria 346 el 11

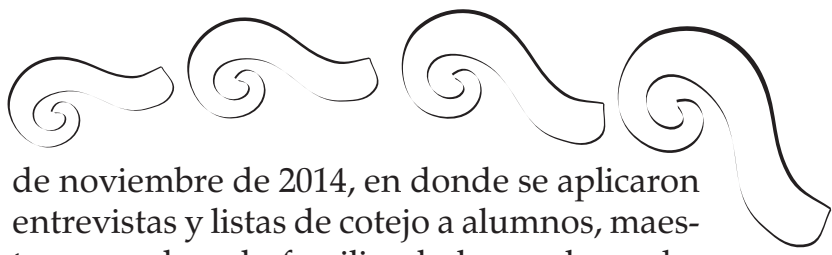

tros y padres de familia, de los cuales se ha obtenido los siguientes resultados:

En el tema de la importancia de estar en la escuela, el $55.5 \%$ de los alumnos menciona que es para tener aquello que no tuvieron sus padres. Por su parte el $40 \%$ de los padres de familia mencionó que la escuela es importante para conseguir un empleo y el otro $40 \%$ para que sus hijos tengan aquello que ellos no tuvieron. Los profesores mencionaron un punto distinto al de los alumnos y padres de familia, el 100\% de ellos acentúa que es para que ellos puedan trascender y formarse integralmente.

En tanto, el $77.7 \%$ de los alumnos y el $60 \%$ de los padres entrevistados con respecto al tema de deserción escolar mencionaron que no sabían lo que significaba este término, por lo que durante la entrevista se les tuvo que explicar a lo que se refería este término. Por otra parte el $100 \%$ de los profesores expresaron que la deserción escolar es cuando los alumnos dejan sus estudios.

Otro de los temas que se trataron durante la entrevista fueron los motivos por el cual los alumnos dejan la escuela, a lo que el $66.6 \%$ de los alumnos, el $80 \%$ de los padres de familia y el $66.6 \%$ de los profesores mencionaron que una de las principales causas de la deserción escolar es la falta de recursos económicos. Esto se pudo corroborar con el recorrido que se hizo por la comunidad y el visiteo, en donde las señoras a quienes se entrevistaron mencionaban que la situación económica en la comunidad era muy precaria y que los jóvenes tenían que salir en busca de trabajo y mejorar sus condiciones de vida. Es por eso que cuando se contrastan con el tema de la participación en la escuela, el $66.6 \%$ de los alumnos menciona que participa activamente en las actividades de la escuela. Asimismo el 60\% de los padres de familia entrevistados afirma que su participación en la escuela es activa y esto en beneficio de sus hijos. 


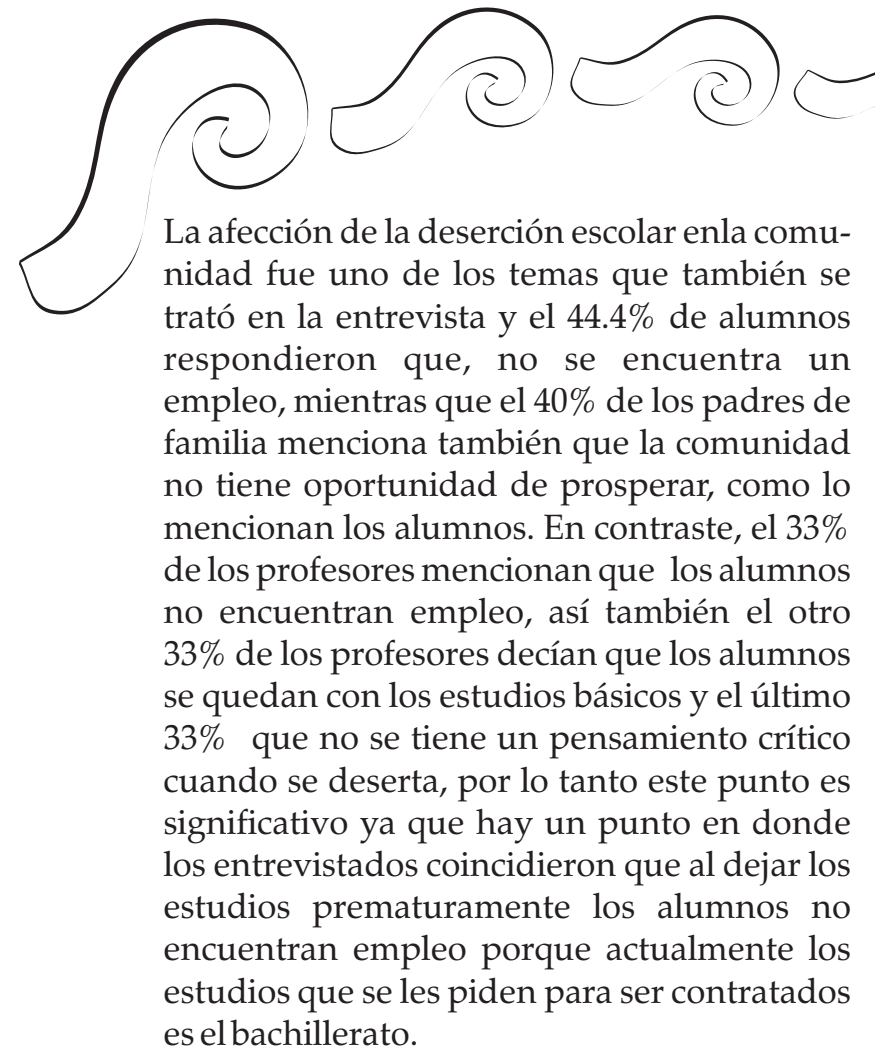

Ante las estrategias que se toman para evitar la deserción escolar el $77.7 \%$ de los alumnos sostienen que una de las maneras para evitarla es esforzarse un poco más en los estudios y colocar lo que está de su parte y en el caso de los padres de familia, saben y son conscientes de la situación económica que viven y que en ocasiones resulta complicado pero el $40 \%$ de ellos quieren que sus hijos continúen con sus estudios y están dispuestos a hablar con ellos para que no los dejen e involucrarse con los maestros y de esta forma estar al pendiente de sus hijos y evitar que dejen su deserción en los estudios. De la misma manera el $60 \%$ de los profesores están dispuestos a hablar con los padres de familia y unir fuerzas para motivar a los alumnos para que continúen con su proceso de formación. Esta información puede corroborarse con uno de los puntos tratados en donde se les preguntaba a los alumnos si eran apoyados por sus padres cuando tenían problemas en la escuela, a lo que el $100 \%$ de los alumnos contestó que sí, así como el 100\% de los padres de familia afirmaron que apoyan a sus hijos, solo que el $66 \%$ de los maestros expresaban que los padres apoyaban a sus hijos cuando estos tenían alguna dificultad en la escuela.
Lo que respecta a los alumnos el $100 \%$ de ellos expresa que repasa sus materias fuera del horario de clase, de la misma manera lo mencionan el 100\% de los profesores ya que ellos mismos son lo que propician esto al preguntarles, ¿por qué estaban seguros de esto? Ellos referían que sí, porque les dejan tareas para que investiguen y repasen lo visto en clase y uno porque como después mencionaban, al $55.5 \%$ de ellos les gustan las materias que llevan en el programa de estudios. Por su parte el $80 \%$ de los padres de familia afirma que sus hijos dedican un tiempo para el estudio. Estos son indicadores significativos porque al continuar con la entrevista el $100 \%$ de los alumnos mencionaba que el profesor les explica y aclara las dudas cuando tienen alguna y de la misma manera y porcentaje lo abordan los profesores, pero el contraste se encuentra en los padres de familia porque solo el $20 \%$ de ellos asegura que el profesor les explica a los alumnos cuando tienen alguna duda.

El ambiente de respeto en el salón también fue unos de los temas abordados, donde el $66 \%$ de los alumnos expresaban que en el salón existe un clima de respeto a comparación de los maestros y padres de familia, quienes afirman que existe respeto en el salón de clases. Quizá las percepciones son distintas porque a quienes les toca vivir de cerca es a los alumnos y no los profesores y padres.

Para cerrar con el análisis de las tablas, el 100\% de los alumnos tiene pensado continuar con sus estudios de bachillerato, ya que al estar motivados por parte de la escuela como lo expresan ellos mismos, los maestros y padres de familia, así como tener los deseos de buscar una nueva calidad de vida, pero sobre todo aprovechar lo que los padres de familia no tuvieron, les gustan las materias que se imparten y esto a su vez repercute en la satisfacción de las materias cuando se estudia.

Para concluir, es necesario retomar dos elementos que no pueden faltar, los recursos con los que cuenta la escuela para satisfacer las 
necesidades escolares de los alumnos y al realizar la encuesta fue posible apreciar que hay carencias en la escuela que en ocasiones limita el aprovechamiento de los alumnos, por ejemplo: la falta de recursos tecnológicos y/o una biblioteca equipada con los títulos necesarios para el nivel, ya que a pesar que las escuelas del próximo nivel escolar están alejadas de su comunidad, ellos hacen el intento de esforzarse para continuar con sus estudios.

\section{Telesecundaria 110, Acapa}

Se realizó una investigación en la comunidad de Acapa el día 12 de noviembre de 2014, en donde se emplearon entrevistas y listas de cotejo a alumnos, maestros y padres de familia. En estos instrumentos obtuvimos los siguientes resultados.

Todos los alumnos dijeron que el apoyo que brinda la escuela es bueno, así como los padres y los maestros a excepción de un maestro que dijo que era regular. La mayoría también coincidió en que lo que le hace falta a la institución son recursos materiales y tecnológicos.

En la pregunta sobre qué importancia tiene estar en la escuela, la mayoría de los alumnos dicen que es para que la persona trascienda al igual que los padres de familia, quienes contestaron lo mismo, así como los maestros.

Las causas del porqué dejan la escuela, el $55.55 \%$ de los alumnos afirmaron que es por la falta de interés, así como el $40 \%$ de los padres que dijeron lo mismo. Aunque el otro $40 \%$ de los padres enunciaron que la causa es por falta de recursos económicos. El 100\% de los maestros dictaron que es por falta de interés.

Los alumnos dicen que la deserción escolar afecta en su comunidad porque la gente se queda con los estudios básicos o nulos. Los maestros dicen que la comunidad no tiene oportunidad de prosperar. Y los padres de familia concuerdan en que los alumnos no encuentran empleo.

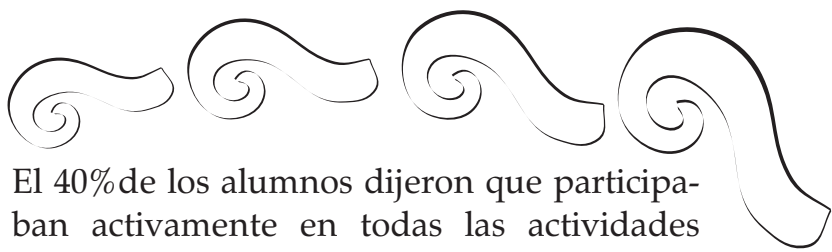
extras de la escuela, mientras que el $30 \%$ dijo que solo asistían a las clases de manera cumplida. Todos coincidieron en que los alumnos repasan sus materias fuera del horario de clases.

La mitad de los alumnos dijeron que para evitar la deserción escolar se debían esforzar más en los estudios. Un maestro dijo que había que concienciar a los alumnos y los padres de familia dijeron que se debíaninvolucrar más con los maestros y con la escuela.

La mayoría dijo que cuando el alumno tiene alguna duda, el maestro la responde. De igual manera coincidieron en decir que los padres de familia apoyan a sus hijos en problemas escolares a excepción de un maestro.

El $60 \%$ de los alumnos dijeron que no existe un ambiente de respeto en el salón de clases. La mitad de los padres enunciaron que sí y todos los maestros afirmaron que sí. Todos coincidieron en que el alumno está a gusto en la escuela y le agrada.

Los maestros determinaron que la falta de bachilleratos cercanos no es un factor de la deserción escolar. La mitad de los padres de familia cuentan con la posibilidad económica para que sus hijos sigan estudiando.

\section{Telesecundaria 598, San Nicolás}

Se realizó una investigación en la comunidad de San Nicolás el día 13 de noviembre de 2014 en donde se emplearon entrevistas y listas de cotejo a alumnos, maestros y padres de familia. En estos instrumentos obtuvimos los siguientes resultados.

El 75\% de los alumnos dijeron que el apoyo de la escuela es bueno, la mayoría de los padres contestó lo mismo y el $66 \%$ de maestros dijeron que éste era regular. Lo que propusieron tanto alumnos, padres de familia y 


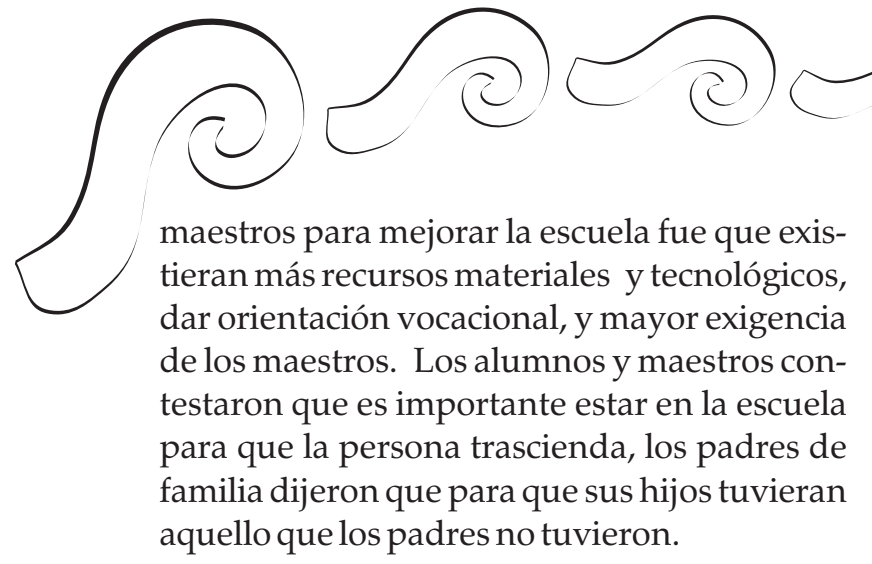

El tema central de por qué los alumnos dejan la escuela, el $62 \%$ de los alumnos y el $60 \%$ de los padres contestaron que era por los recursos económicos. El 66\% de los maestros mencionaron que era por falta de interés. En la cuestión de cómo afecta la deserción en la comunidad, el $62 \%$ de los alumnos y el $60 \%$ de los maestros dijeron que la comunidad no prosperaba. Y el $75 \%$ de los padres de familia dijeron que los alumnos no encuentran empleo.

La participación de los alumnos de la escuela se demuestra que el $62 \%$ participan activamente en todas las actividades extras en la escuela, mientras que el $25 \%$ apoyan y dan ideas al director o a los maestros cuando surge algún problema. El 80\% de los padres de familia participan en actividades en beneficio de los alumnos.

Para evitar la deserción escolar, el 50\% de los alumnos enunciaron que se esforzarían más en sus estudios y el $37 \%$ expidió que pediría ayuda a sus padres. El $80 \%$ de los padres hablarían con sus hijos para que no dejen la escuela.

El 87\% de los alumnos, el 75\% de los padres y el 100\% de los maestros afirman que los alumnos repasan sus materias fuera de los horarios de clase. Todos coinciden que cuando surge alguna duda, el profesor la resuelve. Al igual que todos concuerdan que los padres de familia apoyan a sus hijos cuando surge algún problema en la escuela.

El $87 \%$ de los alumnos, el $75 \%$ de los padres y el $100 \%$ de los maestros acuerda en que existe un ambiente de respeto en el salón. El 100\% de los alumnos, el $75 \%$ de los padres y el $33 \%$ de los maestros desconocen que los alumnos ya no continuarán con sus estudios por irse a trabajar.

El 100\% de los alumnos aclaran que tienen pensado continuar sus estudios de bachillerato, el $66 \%$ de los maestros afirman que la situación económica de las familias contribuye a que los alumnos dejen de estudiar.

\section{Procedimiento}

Las entrevistas y listas de cotejo que se realizaron, manejaban preguntas acerca de la deserción escolar. Los sujetos fueron seleccionados al azar y de forma voluntaria, esto con la finalidad de respetar la naturaleza de los hechos y tratar de realizar una cantidad mínima de alteraciones posibles. Estos instrumentos se fueron aplicando en las horas de clases a los alumnos y maestros y a la hora del almuerzo se les aplicaron a los padres de familia cuando estos llegaban a la escuela con comida preparada para sus hijos.

Antes de hacer las entrevistas y las listas de cotejo, se les explicó a los alumnos, maestros y padres de familia en qué consistían las preguntas; después de la explicación, accedieron a contestar las preguntas sin ningún problema. Las entrevistas para los alumnos y maestros se realizaron en la biblioteca; a los alumnos se les solicitaba que pasaran de tres en tres para que se les pudieran hacer las preguntas, $y$ cuando terminaban se les aplicaba los instrumentos a los maestros, los cuales al ser tres, el tiempo no presentó algún inconveniente. En cuanto se vio que comenzaban a llegar los padres de familia, se logró abordar el tema antes que se retiraran; se les explicó el objetivo de la entrevista y la lista de cotejo, y después de entrar en confianza, se comenzaron las preguntas.

Para la recolección de datos, algunos padres de la comunidad de San Nicolás tuvieron 
dificultad en responder al principio algunas de las preguntas por cuestiones de tiempo y ocupación; pero al final antes de comenzar el taller se completaron dichas entrevistas y listas de cotejo.

\section{Resultados}

La razón de esta investigación fue buscar los motivos de la deserción escolar en la Zona Escolar 55 de telesecundarias. La investigación se realizó en las telesecundarias integradas a esta zona: San Lorenzo Iztacoyotla, Santa María, Acapa y San Nicolás.

A lo que se llegó con esta investigación fue que el $56.06 \%$ de las cuatro comunidades de la Zona Escolar 55 que se entrevistaron, menciona que las razones por la que los alumnos dejan la escuela es por falta de recursos económicos; y el 30.3 \% de la población antes mencionada, afirma que es por la falta de interés en los alumnos. Lo anterior se puede demostrar en los siguientes resultados:

En San Lorenzo el 66.6\% de los alumnos, el $80 \%$ de los padres de familia y $100 \%$ de los maestros, dijeron que la razón por la que los alumnos dejan la escuela es a causa de faltas de recursos económicos.

En Santa María el $66.6 \%$ de los alumnos, el $80 \%$ de los padres de familia y el $66.6 \%$ de los profesores, mencionaron que una de las principales causas de la deserción escolar es la falta de recursos económicos.

En Acapa las causas de por las que dejan la escuela: el $55.55 \%$ de los alumnos afirmaron que es por la falta de interés, así como el $40 \%$ de los padres reafirmaron esto y el $100 \%$ de los maestros dictaron que es por falta de interés. Aunque el otro $40 \%$ de los padres anunciaron que la causa es por falta de recursos económicos. Por lo tanto el $56 \%$ de los entrevistados dijeron que la causa de deserción escolar es por falta de interés.

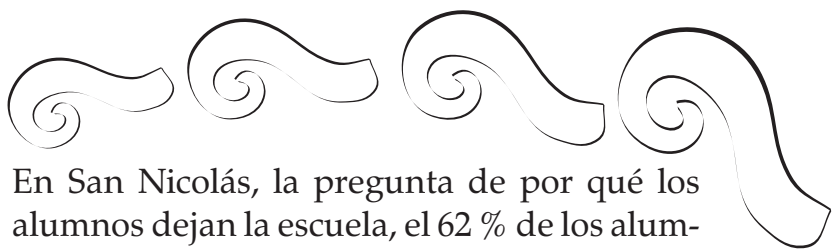
nos y el $60 \%$ de los padres contestaron que era por los recursos económicos. El $66 \%$ de los maestros dijeron que era por falta de interés. Por lo tanto el $50 \%$ de la población de San Nicolás anunciaron que es por falta de recursos económicos y el $37 \%$ afirma que la causa es por la falta de interés.

De acuerdo a cada una de las entrevistas realizadas en cada una de las telesecundarias, éste fue el resultado que nos arrojó.

Crispo (2001) menciona que los índices de escolarización en los países industrializados han aumentado, de igual forma han aumentado los índices de jóvenes que fracasan o se encuentran marginados antes de haber terminado su escolaridad obligatoria y en donde las clases menos favorecida no continúan con sus estudios del ciclo básico. El aspecto económico vinculado al aspecto sociológico, es uno de los detonantes de la deserción escolar en estas escuelas, ya que las condiciones económicas son precarias.

Es notable en estas comunidades que los padres de familia están al pendiente de los alumnos, asisten a las pláticas que se imparten, están al pendiente de las calificaciones pero algo significativo y que se observó en las cuatro escuelas, fue la mayoría de los padres de familia acude a la escuela todos los días y llevan a sus hijos el almuerzo en la hora del receso. No fue posible ahondar en las situaciones familiares que viven los alumnos en sus familias, pero un punto que salió en las entrevistas fue que la mayoría de los padres de familia asisten a las pláticas como por ejemplo, al taller que se propuso para no perder el apoyo que reciben del gobierno como "Prospera", por lo que se puede suponer que esta participación es condicionada.

En otro de los temas abordados durante la investigación de campo, se puede rescatar que los profesores utilizan distintas estrategias 


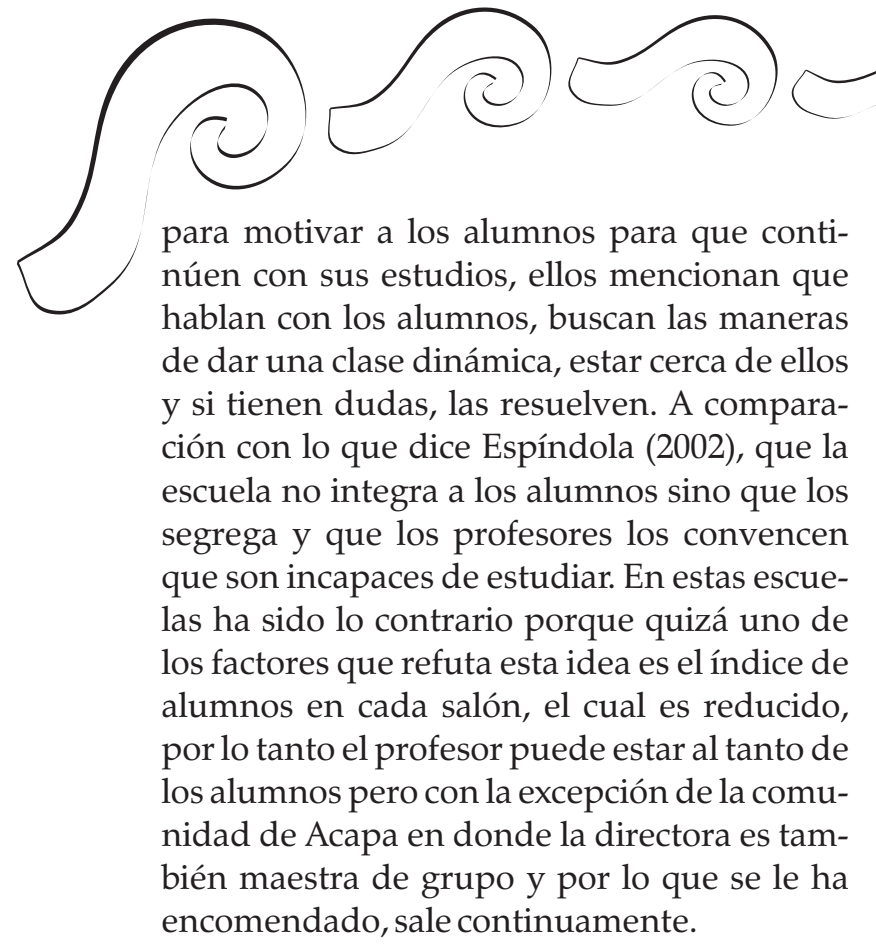

\section{Conclusiones}

Si partimos del planteamiento del problema que se hizo al principio de esta investigación y del trabajo exploratorio en donde se detectó la problemática de la deserción escolar en los alumnos. Se puede concluir que la deserción escolar está presente pero en las cuatro telesecundarias en las que estuvimos recolectando información, la respuesta que se obtuvo fue que el factor principal de la deserción escolar es la falta de recursos económicos, ya que los materiales y pasajes; cuando los alumnos se van a otra comunidad a estudiar, suponen un gasto fuerte para la familia. La segunda causa es por falta de interés en los alumnos.

Los aspectos académicos no influyen considerablemente en la deserción escolar, puesto que el $4.5 \%$ de la población menciona que se da por problemas de aprendizaje, sin embargo, la falta de recursos materiales, por ejemplo: libros de consulta, computadoras, elementos que sirven para complementar el trabajo de los alumnos.

Los padres de familia apoyan a sus hijos y los deseos que tienen es que aprovechen y puedan lograr lo que ellos no han tenido.
Por otra parte, lo que hacen para evitar la deserción en los alumnos es que les dan todo lo que está dentro de sus posibilidades y se apoyan también en las becas para los alumnos que les da el gobierno.

Los docentes por su parte también intervienen en el proceso de los alumnos y buscan dentro de sus posibilidades evitar que ellos dejen la escuela y los animan a continuar con sus estudios, por ejemplo: explican cuando los alumnos no entienden algún concepto o tienen alguna duda de la materia, o cuando les comparten sus dificultades les aportan y motivan a que busquen otras soluciones.

De lo que se pudo encontrar al realizar las entrevistas en los diferentes temas, tanto con alumnos, maestros y padres de familia, fue que los alumnos mencionan que esforzarse en sus estudios les llevaría a tener un mejor aprovechamiento en sus materias. Por su parte, los profesores unen fuerzas con los padres de familia para evitar esta situación con el alumno y donde ellos dicen que a pesar de la situación económica que viven, están dispuestos a apoyar a sus hijos en la continuidad de sus estudios.

Aunado a esto, el 100\% de los alumnos de las cuatro telesecundarias entrevistadas de la zona 55, tienen pensado continuar con sus estudios a nivel bachillerato y el $72 \%$ de los padres de familia expresan que apoyarán en la medida de sus posibilidades para que sus hijos concluyan sus estudios; mientras que el $22.78 \%$ no cuenta con posibilidades económicas, pero a pesar de esa limitante, apoyarán a sus hijos en la medida de lo posible.

El efecto de la deserción escolar en la comunidad fue otro de los temas abordados en la entrevista: el $31.25 \%$ de la población respondieron que no encuentran un empleo, por otro lado, el 29.68\% menciona que la comunidad no prospera, el $32.8 \%$ afirman que se queda con los estudios básicos. 
La participación de los alumnos de la escuela demuestra que el $17.57 \%$ participan activamente en todas las actividades extras en la escuela, mientras que el $10.7 \%$ apoyan y dan ideas al director o a los maestros cuando surge algún problema. El $61.11 \%$ de los padres de familia participan en actividades en beneficio de los alumnos, el $33.33 \%$ de los padres afirman que están al pendiente de sus hijos y cómo van en la escuela.

Para evitar la deserción escolar, el 60\% de los alumnos enunciaron que se esforzarían más en sus estudios, el $14.28 \%$ expidió que pediría ayuda a sus padres. El $44.44 \%$ de los padres hablarían con sus hijos para que no dejen la escuela, el $38.88 \%$ anunció que se involucrará con el maestro.

El $85.9 \%$ de la población afirma que los alumnos repasan sus materias fuera de los horarios de clase.

El 78.12\% acuerda en que existe un ambiente de respeto en el salón. El 100\% de los alumnos aclaran que tienen pensado continuar sus estudios de bachillerato. El $81.8 \% \%$ de los maestros afirman que la situación económica de las familias contribuye a que los alumnos dejen de estudiar.

\section{Aportaciones del trabajo}

La investigación realizada dio pautas para tener en cuenta que no son los problemas cognitivos ni las situaciones familiares, tampoco la falta de escuelas en la zona, las que provocan que los alumnos dejen sus estudios sino la falta de recursos los que lo propician.

\section{Limitaciones}

Las limitaciones que se tuvieron para la realización de esta investigación fueron:

- Tiempo: se estuvo poco tiempo en una comunidad, ya que en cada día se destinó para una comunidad diferente y esto impidió tener un contacto más

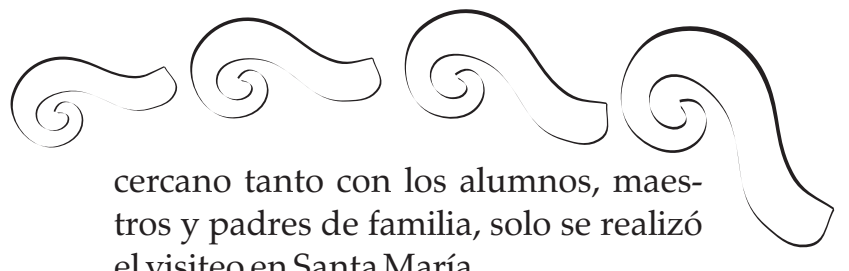
el visiteo en Santa María.

- Clima: el clima no favoreció del todo porque una de las compañeras se enfermó a causa de éste y en las cuatro comunidades el clima era frío.

Cada una de estas limitaciones fueron acogidas favorablemente por el grupo. En cuestión del tiempo, el grupo se pudo adaptar a ellos; las entrevistas se realizaron en los tiempos previstos y los tiempos del taller fueron los óptimos ya que al ser lo suficiente, no se apresuró el trabajo ni los padres de familia se aburrieron en él.

Por otra parte, el clima no impidió realizar las actividades previstas, se realizaron las entrevistas en espacios cerrados ya que al estar tan frío esto nos pudo haber provocado algún problema de salud.

\section{Sugerencias}

1. Involucrar más a los padres de familia en actividades de la escuela que tengan que ver con sus hijos. Para prevenir la deserción escolar sugerimos la elaboración de talleres que hablen de la adolescencia y la deserción escolar.

2. Generar una mayor confianza de los alumnos hacia los maestros, pues en las entrevistas pudimos observar que no todos los estudiantes le tienen la confianza a los profesores para contarles lo que les ocurre. Esta confianza se puede realizar a través de integraciones grupales o excursiones.

3. Llevar un registro de ex alumnos para seguirles la pista y así cuidar a cada alumno para evitar la deserción escolar, y con esto aprovechar alguna experiencia de los egresados

4. Atención a jóvenes en riesgo. Bajo esta estrategia se le brindará atención personal al estudiante en riesgo, esta atención se puede brindar a través de las 


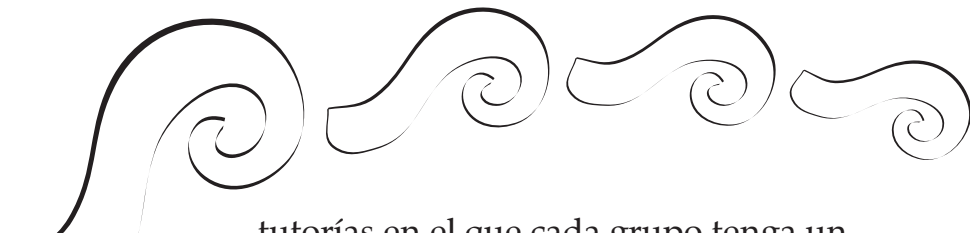

tutorías en el que cada grupo tenga un profesor tutor que asesore y emplee entrevistas para localizar y prevenir problemas de riesgo en los alumnos. (Aponte, E. (1988).

5. Establecer expectativas altas en las áreas de asistencia, aprovechamiento académico y disciplina. Se ha comprobado que al mantener una expectativa alta de las ejecutorias de los estudiantes, estos desarrollan el autoestima indispensable para el éxito académico. Entre la alternativa que se sugiere dentro de esta estrategia está extender el horario escolar, clases los fines de semana, escuela de verano, tutorías, programas transaccionales, ayuda remediativa y programas motivacionales. (Aponte, E. (1988).

6. Seleccionar y capacitar a maestros para que sean receptivos a las necesidades del estudiante en riesgo. Es importante que los maestros tengan la capacidad de escuchar para poder orientarlos en forma adecuada. (Aponte, E. (1988).

7. Invitar a los padres de familia a que el apoyo que reciben del gobierno sea bien invertido y no sea solamente un modo de tener un recurso y gastarlo en algo innecesario.
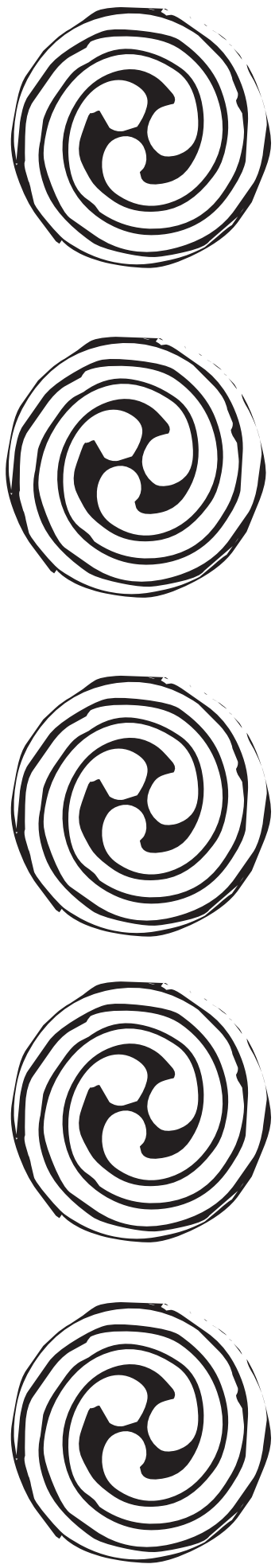


\section{Fuentes de consulta:}

Aponte, E. (1988). Perfil del desertor escolar y estrategias para retenerlo. Pedagogía, 25 (No. 2.) Recuperado el 23 de noviembre de 2014, de: http://www.monografias.com/ trabajos22/desercion-escolar/desercion-escolar.shtml\#ixzz3K6rUPIYH

Callabed Joaquín. (2002). El niño y la escuela. Dificultades escolares. Barcelona: Laertes.

Cárdenas, D. S. Esperanza para la Familia. Obtenido de Esperanza para la Familia: http://www.esperanzaparalafamilia.com/Rev/Articulos/PDFs/PDF0129.pd (15 de Septiembre de 2014).

Crispo, D. G. (2001). Adolescencia y trastornos del comer. Barcelona, España: gedisa.

Del Castillo, M. (2012). Causas, Consecuencias y prevención de la deserción escolar. EUA: Palibrio.

Espinoza, O., Castillo, D., González, L., \& Loyola, J. (2012). Factores familiares asociados a la deserción escolar en Chile. Redalyc, XVIII, 147.

Espíndola, E. (2002). La deserción escolar en América Latina: un tema prioritario para la agenda regional. Revista Iberoamericana de Educación, 39-62.

Hurlock, E. (2007). Psicología de la adolescencia. México: Paidós.

INNE. (2010).Panorama Educativo de México. Tasa de deserción total (2008/2009). Documento recuperado el 23 de septiembre de 2014 desde: http://www.inee.edu.mx/bie/mapa_indica/2010/PanoramaEducativoDeMexico/AT/AT02/2010_AT02_d-vinculo.pdf

Jiménez Hidalgo, J. d., Martínez Jiménez, R., \& García Mancilla, C. D. (2010). La Telesecundaria en México: un breve recorrido histórico por sus datos y relatos. México. Distrito Federal: Secretaría de Educación Pública.

La Salle. (2011). Proyecto Educativo Regional Latinoamericano.

Papalia, D. E., Wendkos, S., \& Duskin Feldman, R. (2005). Desarrollo Humano. Mexico: McGrall Hill.

RAE. (s.f.). Diccionario de la Lengua Española. Recuperado el 15 de 09 de 2014, de Real Academia Española (RAE): http://lema.rae.es/drae/?val=deserci\% C3\%B3n+escolar

Santillana (1983). Diccionario de las Ciencias de la Educación, A-H, Madrid, España: DiagonalSantillana
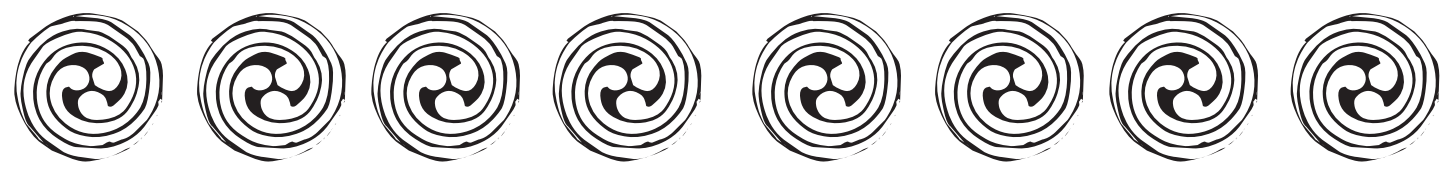

๑5 @ 
Anexos

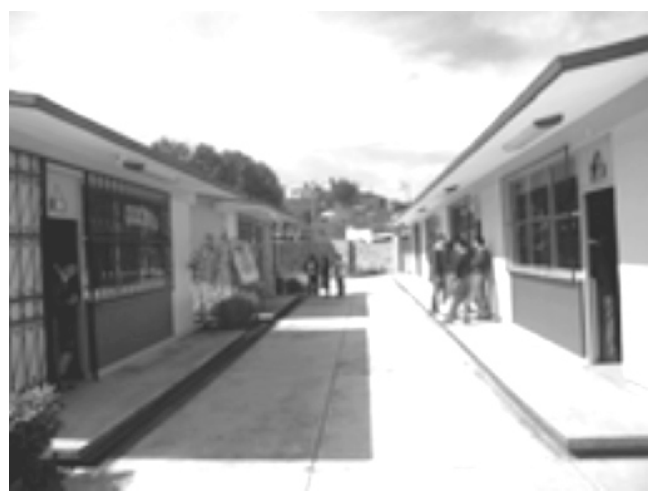

Telesecundaria 346, Santa María

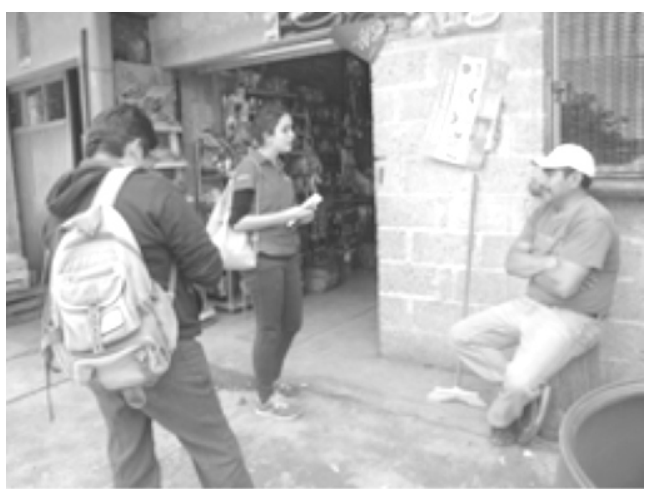

Visiteo

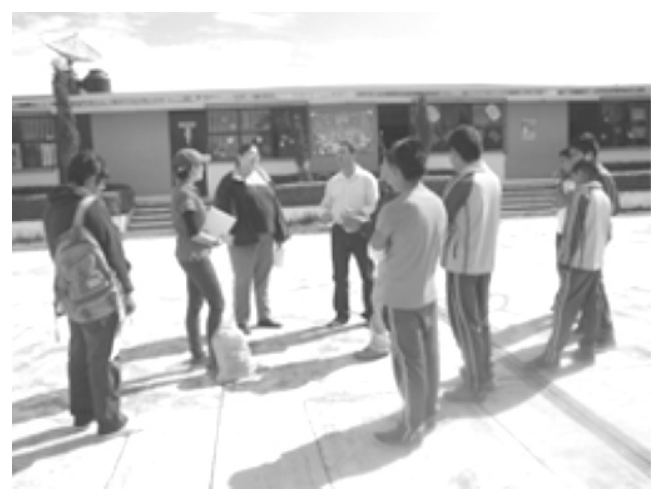

Taller de Padres

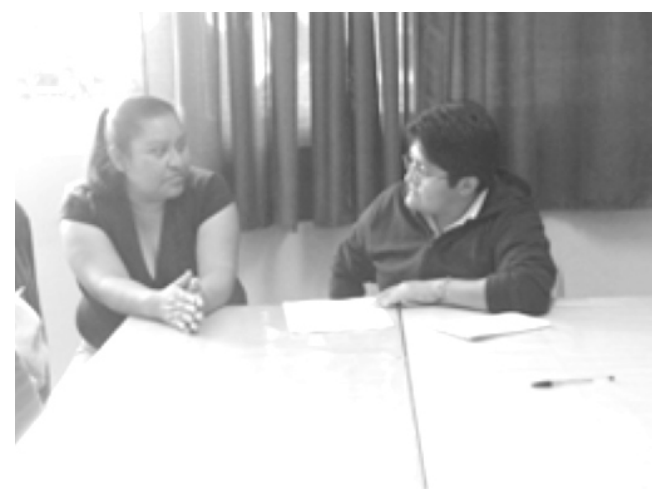

Telesecundaria 22, San Lorenzo

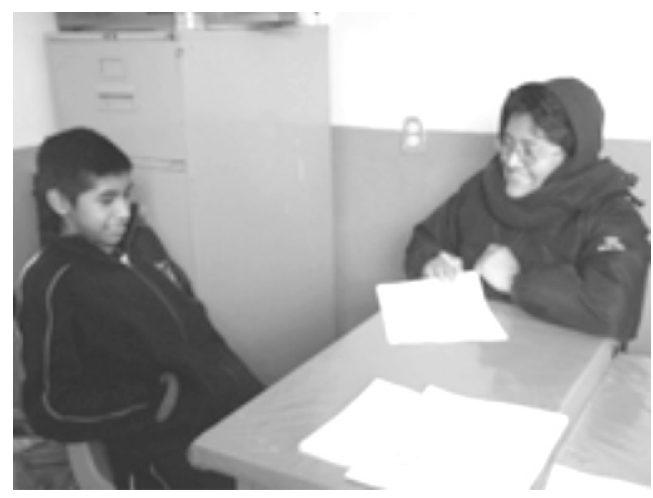

Entrevista a alumnos

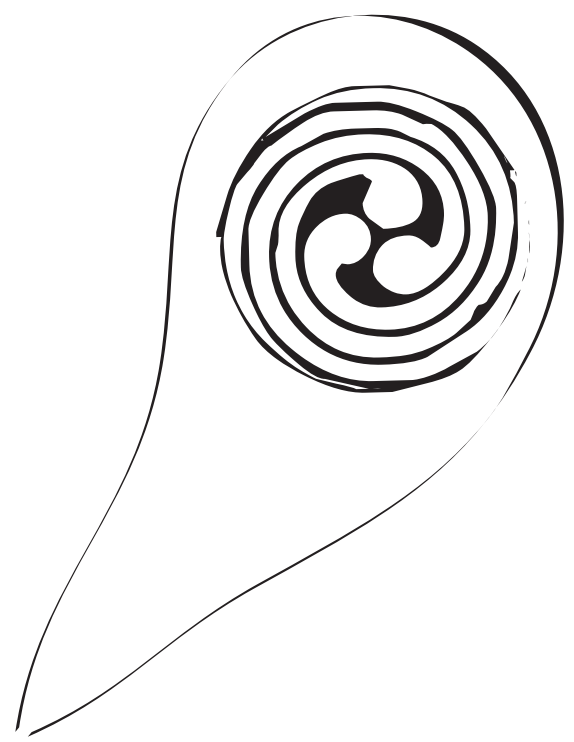




$$
\rho^{\infty}
$$

